\title{
Green synthesis of iron oxide nanoparticles using Ceratonia siliqua $L$. aqueous extract: Optimization, characterization, stabilization and evaluation of its antibacterial activity against gram-positive and gram-negative bacteria
}

Derya Aksu Demirezen ( $\nabla$ dademirezen@gmail.com )

Erciyes Üniversitesi: Erciyes Universitesi https://orcid.org/0000-0002-1979-9903

Şeyda Yılmaz

Dilek Demirezen Yılmaz

Yalçın Şevki Yıldız

\section{Research Article}

Keywords: Green synthesis, Iron oxide nanoparticles, Antibacterial activity, Process optimization, Stability

Posted Date: February 11th, 2022

DOI: https://doi.org/10.21203/rs.3.rs-1302371/v2

License: (c) (1) This work is licensed under a Creative Commons Attribution 4.0 International License.

Read Full License 


\section{Abstract}

This study focused on the optimization of reaction parameters for a simple and reliable method for the green synthesis of iron oxide nanoparticles (glONPs). The potential of aqueous extract of the Ceratonia siliqua L. (carob pod) as a reducing, capping, and stabilizing agent for gIONPs synthesis, and the antibacterial activity of as-synthesized gIONPs was investigated. The synthesis parameters were determined as the concentration of iron ion, the concentration of extract, $\mathrm{pH}$ of extract, temperature, stirring rate, and reaction time. The significance of the studied factors in controlling the particle size distribution of nanoparticles was quantitatively evaluated via analysis of variance (ANOVA). Iron oxide nanoparticles were produced at the optimum parameters with an average zeta potential of $+40.75 \pm 1.22$ $\mathrm{mV}$, hydrodynamic size of $78 \pm 22 \mathrm{~nm}$, and a polydispersity value of $0.42 \pm 0.06$, respectively. gIONPs showed the highest inhibition zones of $24 \mathrm{~mm}$ and $21 \mathrm{~mm}$ in $250 \mathrm{mg} / \mathrm{mL}$ concentration against Gramnegative Escherichia Coli and Gram-positive Staphylococcus aureus, respectively. Antibacterial activity was observed when compared with the standard antibiotics. The findings of the study revealed that the highly stable and antibacterial iron oxide nanoparticles can be synthesized through the adjustment of the reaction parameters by eliminating chemicals.

\section{Introduction}

Nanoparticles have been prepared through a diverse range of synthesis approaches over the last decades and different fundamental principles of synthesis procedures have been investigated to obtain nanoparticles of desired sizes, shapes, and functionalities. Their unique size-dependent thermal, electrical, chemical, and optical properties have enabled their use in fields as medicine and chemical analysis [1].

The green synthesis approach is a promising synthesis procedure in the research and development of materials science and technology due to the biosynthetic pathway of nanoparticles preparation, potentially eliminating the usage of chemicals and making the nanoparticles more biocompatible. Some basic principles of "green synthesis" can be explained by prevention or minimization of waste, reduction of pollutant derivatives, and the use of safer solvent as well as renewable feedstock [2]. The biomaterials extracted from several parts of the plant are mixed with metal precursor solutions at different reaction conditions for nanoparticle synthesis. The biomaterials play several roles such as reducing, capping, and stabilizing agents in the nanoparticle synthesis process. Nanoparticles are synthesized within a few minutes or hours depending upon the type and concentration of biochemicals arising from plant sources. The plant extracts have been proven to possess high efficiency as stabilizing and reducing agents for the synthesis of nanoparticles but detailed investigation on the role of reaction parameters in synthesis is still needed to overcome existing problems in 'green' synthesis [3].

Capping agents significantly modify the properties of colloidal suspensions of nanoparticles. The efficacy of colloidal NPs application is linked to high suspension stability. Small changes to the solution (e.g., background salt concentration, temperature, $\mathrm{pH}$ ), or changes to the nanoparticles (e.g., surface 
coating or concentration) can substantially affect stability. There are several parameters that affect the green synthesis of nanoparticles, including $\mathrm{pH}$ of the solution, temperature, the concentration of the plant material used, reaction time, and above all the protocols that are used for the synthesis process. The change in the type and characteristic of the synthesized nanoparticles is especially affected by the type of plant material used in the synthesis process [4]. The morphology and surface property of nanoparticles are important parameters for their applications. The better antibacterial action may be attributed to their smaller size and surface charge to come in contact with the microbial cells [5]. An ideal synthesis method should be able to allow reliable adjustment of particle distribution, size, and composition [6].

There are different phases of iron oxides as hematite $\left(\mathrm{a}-\mathrm{Fe}_{2} \mathrm{O}_{3}\right)$, maghemite $\left(\mathrm{\gamma}-\mathrm{Fe}_{2} \mathrm{O}_{3}\right)$, goethite ( $\mathrm{a}-$ $\mathrm{FeOOH})$, and magnetite $\left(\mathrm{Fe}_{3} \mathrm{O}_{4}\right)$. The size scale affects the optical, electrical, and biocompatibility properties of these materials [7] [8]. The functional groups of coating materials alter the surface charge, which influences the biological behaviors of iron oxide nanoparticles [9]. The dispersity, size, and surface chemistry of the iron oxide materials are crucial for environmental applications in the aqueous phase due to the porous structure with particle-surface interaction [10]. Iron oxide nanoparticles act as promising antibacterial agents that have high surface areas with crystalline morphologies at a high number of edges and corners and generation oxidative stress by reactive oxygen species [11].

In this study, we report the green synthesis of iron oxide nanoparticles using biochemicals extracted from Ceratonia siliqua. L. (carob pod). Carob pod is rich in sugars as sucrose ( $437.3 \mathrm{mg} / \mathrm{g}$ dry weight), glucose (395.8 mg/g dry weight), and fructose ( $42.3 \mathrm{mg} / \mathrm{g}$ dry weight). The other content is as total phenolics group (13.51 mg gallic acid equivalents [GAE]/g dry weight), proanthocyanidins ( $0.36 \mathrm{mg} \mathrm{GAE} / \mathrm{g}$ dry weight), gallotannins ( 0.41 catechin equivalents [CE]/g dry weight), and flavanols (3.21 mg CE/g dry weight protein). Gallic acid (3.27 mg/g dry weight) is the most abundant phenolic material. Aspartic acid $(18.25 \mathrm{mg} / \mathrm{g}$ dry weight protein) is the predominant amino acid in the protein fraction. Major minerals are vitamin $\mathrm{K}$, calcium, potassium, and magnesium [12].

The effects of reaction parameters on the synthesis of iron oxide nanoparticles were investigated by the Taguchi method in this study. The Taguchi method is used for evaluating the results of matrix experiments to determine the best levels of experimental parameters. It makes it possible to provide an acceptable formulation using minimum raw materials and time [13]. The signal-to-noise $(\mathrm{S} / \mathrm{N})$ ratio and the analysis of variance (ANOVA) were employed to analyze the experimental parameters. The parameters including the concentration of plant extract, the concentration of iron ion, reaction temperature, $\mathrm{pH}$ of plant extract, stirring rate, and reaction time were evaluated. The polydispersity value of nanoparticles was measured by a dynamic light scattering (DLS) instrument after each synthesis to analyze the effect of chosen experimental parameters. The zeta potential and UV-Vis spectrum was monitored over 3 months period for analysis of colloidal stability. Furthermore, the antibacterial activity of powder gIONPs were tested against Gram-negative (Escherichia coli) and Gram-positive (Staphylococcus aureus) bacteria. 


\section{Materials And Methods}

\section{Materials}

Carob pod was purchased from the local market in Kayseri, Turkey. Ferric chloride $\left(\mathrm{FeCl}_{3} \cdot 6 \mathrm{H}_{2} \mathrm{O}\right)$, sodium hydroxide $(\mathrm{NaOH})$ and hydrochloric acid $(\mathrm{HCl})$ were purchased from Merck. Ultrapure water was used in the experiments (Elga Purelab Option-Q 7).

\section{Synthesis and characterization of gIONPs}

The method for the extraction of the carob pod was used as similar to the procedure followed in our previous study [14]. $10 \mathrm{gr}$ of carob pod pieces were extracted in $150 \mathrm{~mL}$ of ultrapure water for 2 hours. The resultant extract was filtered through Whatman No.1 filter paper and was used as a reducing and capping agent for the green synthesis of iron oxide nanoparticles. $3.8 \mathrm{~g}$ of ferric chloride $\left(\mathrm{FeCl}_{3} \cdot 6 \mathrm{H}_{2} \mathrm{O}\right)$ was dissolved in $100 \mathrm{~mL}$ of ultrapure water for $15 \mathrm{~min}$. The extract to precursor iron solution was mixed at a 1:1 volume ratio. The addition of the plant extract to ferric chloride aqueous solution led to turning initially yellowish solution to a brown color indicating the formation of iron nanoparticles. The resultant colloidal nanoparticle solution was stirred for 3 hours and kept in a $+4{ }^{\circ} \mathrm{C}$ refrigerator to do stability analysis. Nanoparticles were precipitated by adjusting the $\mathrm{pH}$ value of gIONPs colloidal solution to 7 and the pellet was washed with ultrapure water and ethanol twice. It was dried in a laboratory oven at $70^{\circ} \mathrm{C}$ for $10 \mathrm{~h}$. The brownish-black powder of glONPs (Fig.S1) was used for characterization and antibacterial analysis.

The characterization of the gIONPs was investigated using X-ray powder diffraction (XRD Bruker AXS D8), SEM energy dispersive (SEM - LEO 440) X-ray (EDX) mapping, and Fourier-transform infrared spectroscopy (FTIR Perkin Elmer 400). Instrumental analysis was performed by the Nanotechnology Research Center (ERNAM) and Technology Research Center (TAUM), Erciyes University. Transmission electron microscopy (TEM) images were recorded using the JEOL 1220 JEM TEM of the Eskişehir Osmangazi University Research Laboratory Application and Research Center (ARUM). The size and dispersity of nanoparticles were analyzed using a dynamic light scattering (DLS) instrument (Horiba nanoPartica SZ-100V2), NanoBiotech Research Laboratory.

The average crystallite size of glONPs was determined by Debye-Scherrer equation $d=(k \lambda / \beta \cos \theta)$, where $\mathrm{k}$ is the Debye-Scherrer constant ( 0.94 for FWHM of spherical crystals with cubic symmetry), $\lambda$ is the $\mathrm{X}$ ray wavelength $(0.154 \mathrm{~nm}), \beta$ is the width of the peak with the maximum intensity in half height, $d$ is the thickness of the crystal, and $\theta$ is the diffraction angle (radian). Origin 2021b (C 1991-2021 OriginLab Corporation) was used for the calculation of the FWHM of XRD peaks for the calculation of $\beta$.

\section{Design of experiment and analysis}

In this study, the design of experiment (DOE) strategy and the Taguchi method for the experimental design approach was used to find optimum experimental conditions of the gIONPs with the minimum 
polydispersity index value (PDI). The goal was the investigation of the six parameters of synthesis including temperature (Temp), $\mathrm{pH}$ of carob pod extract, extract concentration of carob pod, the concentration of iron ion, stirring rate (RPM), and reaction time (time). Six experimental parameters used for the green synthesis of iron oxide nanoparticles and their corresponding three levels are represented in Table 1. The analysis of variance (ANOVA) was used to determine the significance of individual parameters for the control of the final response.

Table 1. Experimental parameters for gIONPs and corresponding levels.

\begin{tabular}{|l|c|c|c|}
\hline Parameters & \multicolumn{3}{|c|}{ Levels } \\
\cline { 2 - 4 } & Low & Center & High \\
\hline pH of carob pod extract & 5 & 8 & 11 \\
\hline Temperature $\left({ }^{\circ} \mathrm{C}\right)$ & 25 & 55 & 85 \\
\hline Carob pod extract concentration $(\% \mathrm{mg} / \mathrm{mg})$ & 5 & 10 & 20 \\
\hline Concentration of iron ion $(\mathrm{M})$ & 0.07 & 0.14 & 0.28 \\
\hline Stirring rate $(\mathrm{rpm})$ & 200 & 400 & 600 \\
\hline Reaction Time $(\mathrm{h})$ & 1 & 2 & 3 \\
\hline
\end{tabular}

The $\mathrm{S} / \mathrm{N}$ ratio and the analysis of variance (ANOVA) with a significance level of 0.05 were employed to study the contributions of the parameters to the response. The Minitab software version 13 (Ankara, Turkey) as a tool for statistical design of experiment was used. The equivalent volume of the gIONPs suspension $(2 \mathrm{~mL})$ was diluted with a constant volume $(2 \mathrm{~mL})$ of deionized water and then subsequently all measurements were performed at room temperature at the DLS instrument. The experiments of 27 runs with 3 trials were conducted for three levels of six parameters.

\section{Stability analysis of gIONPs}

The zeta potential measurement of the colloidal gIONPs samples was determined using a zeta potential analyzer (Horiba nanoPartica SZ-100V2). The method used by the SZ-100V2 is known as laser Doppler electrophoresis. The sample was irradiated with a laser light of $532 \mathrm{~nm}$ at 3.3 electrode voltage. A cell with an electrode was used to introduce an electric field into the sample. All presented zeta potentials were reported as the mean value of three independent measurements at $25^{\circ} \mathrm{C}$ temperature. UV-Visible spectroscopy (Hach DR 6000 UV-Vis spectrophotometer) was used for monitoring the maximum absorbance of nanoparticles over time. The UV-Vis spectrum of the gIONPs sample at a dilution ratio of $1: 10(\mathrm{v} / \mathrm{v})$ was monitored using a $1 \mathrm{~cm}$ glass cuvette. The absorbance spectrum was obtained between $200-700 \mathrm{~nm}$. The stability analysis was performed for 3 months.

\section{Antibacterial activity analysis of gIONPs by well-diffusion method}


The bacterial culture and antibiotic discs were obtained from the Veterinary Medicine Faculty Laboratory of Erciyes University. The bacterial activity of gIONPs was performed against both Gram-negative (Escherichia coli 0157:H7) and Gram-positive (Staphylococcus aureus ATCC 25923). The antibacterial activity analysis was performed due to the Kirby-Bauer well diffusion method. Briefly, the selected bacterial pathogenic strains were subcultured on Mueller-Hinton nutrient broth. Each strain was spread uniformly on nutrient agar plates using a sterile cotton swab. A sterile cork borer was used to create a well of about $8 \mathrm{~mm}$ diameter for testing the antibacterial activity of gIONPs. $250 \mathrm{mg}$ of gIONPs was dispersed in $1 \mathrm{~mL}$ of water. $100 \mu \mathrm{L}$ of gIONPs was loaded into the well (8 mm diameter) on the MullerHinton agar plate. Antibiotics of Cefoxitin $(30 \mu \mathrm{g} /$ disc), Cefotaxime $(30 \mu \mathrm{g} / \mathrm{disc})$, Gentamicin (10 $\mu \mathrm{g} /$ disc), and Tetracycline ( $30 \mu \mathrm{g} / \mathrm{disc}$ ) were used as a positive control. The extract of Ceratonia siliqua $L$. $(100 \mu \mathrm{L})$ was used as a negative control. Then the plates were incubated at $37^{\circ} \mathrm{C}$ for $24 \mathrm{~h}$. The different zone levels of inhibition were measured and analyzed according to the Kirby Bauer Interpretation chart (Table S3). The average values of triplicate measurements were calculated as an outcome of antibacterial activity.

\section{Results And Discussion}

\section{Optimization of gIONPs synthesis parameters}

Taguchi experimental design was employed based on the L27 orthogonal array for three levels of six parameters. The goal was the investigation of the six parameters of synthesis including the concentration of carob pod extract, the concentration of iron ion, temperature, $\mathrm{pH}$ of carob pod extract, reaction time, and stirring rate. Supplementary Table S1 shows the 27 experimental runs with their responses of hydrodynamic size and polydispersity (PDI) value according to the DLS measurements. The term "polydispersity "is used to describe the degree of non-uniformity of size distribution. The numerical value of PDI ranges from 0.0 (perfectly uniform sample) to 1.0 (multiple particle size populations) and is measured by the dynamic light scattering (DLS) technique [15].

The S/N ratio results of each parameter effect on the PDI of gIONPs are presented in Fig. 1 as graphs. The highest $\mathrm{S} / \mathrm{N}$ ratios were selected for the smallest PDI value response. The response table for the $\mathrm{S} / \mathrm{N}$ ratios of parameters is shown in Table 2. According to their larger value of delta, the parameters were assigned as rank $1,2,3,4,5$, and 6 . Rank 1 means the highest contribution parameter for the lowest PDI value while rank 6 means the lowest contribution parameter.

The reaction time is the highest contribution parameter while the $\mathrm{pH}$ of the carob pod extract is the least contribution parameter. The optimum parameter levels for the smallest PDI value were determined as $0.14 \mathrm{M}$ iron ion concentration, $10 \%$ extract concentration, extract $\mathrm{pH}$ of $5,25^{\circ} \mathrm{C}$ temperature, stirring rate of $400 \mathrm{rpm}$, and reaction time of 3 hours (Fig.1). Plant extract is the dominant parameter in nanoparticle synthesis, as it is the source of reducing agents and stabilizing molecules. Increasing the plant concentration from $10 \%$ to $20 \%(\mathrm{w} / \mathrm{w})$ increased the PDI of the nanoparticles, while also causing agglomeration at $30 \%$. Meantime, enhancement of the reaction time from 1 to 3 hours lead to 
nanoparticles with the smallest size. The stirring rate and $\mathrm{pH}$ of carob pod extract did not make a huge difference to the response. The direct effect of temperature may be due to enhancing the rate of nanoparticle formation [16]. The pH change at the carob pod extract might not have altered the electrical charges of biomolecules and capping agents and their ability to bind and reduce metal ions [17]. The stirring rate of $400 \mathrm{rpm}$ was observed as a transition condition between the stirring rate of 200 and 600 rpm for the smallest size and polydispersity index. The low stirring rate was proved unable to produce iron oxide nanoparticles. The high mixing rate might have caused the nanoparticles to have high surface energy and caused their agglomeration [18]. Analysis of variance (ANOVA) showed that the significance level of the studied parameters in Table 3. The results indicate that iron ion concentration, reaction time, temperature, and carob pod extract concentration had a significant effect on PDI value ( $p$-value $<0.05)$.

There are several studies about the procedure optimization of the green synthesis of several nanoparticles such as silver, zinc, and gold, etc. in the literature. The green synthesis of nanoparticles is related to various factors, including types of plant biomolecules and concentration, $\mathrm{pH}$, temperature, stirring rate, and exposure time. These factors are found to control the sizes and morphologies of the nanoparticles according to the literature [19] [20] [21] [22]. The effects of various parameters in the green synthesis method of iron nanoparticles such as iron precursor, plant extract concentration, reaction temperature, and $\mathrm{pH}$ have been studied little when the studies in the literature are reviewed. Kheshtzar et.al. reported that the quantity of leaf extract and concentration of iron precursor is the most effective parameters in the green synthesis reaction [23]. It was revealed by Gholami et.al. that the iron precursor to extract ratio has a significant effect on green iron nanoparticles synthesis [24].

Table 2. Response table for $\mathrm{S} / \mathrm{N}$ ratios of PDI

\begin{tabular}{|c|c|c|c|c|c|c|}
\hline Level & Extract Concentration & $\underline{\text { Iron Ion }}$ & $\underline{\text { Time }}$ & $\underline{\text { Temp }}$ & $\underline{\text { RPM }}$ & pH \\
\hline 1 & -12.1849 & -13.5807 & -15.2026 & -7.3956 & -11.2539 & -10.3223 \\
\hline 2 & -7.4894 & -6.3857 & -11.2326 & -15.4661 & -10.1172 & -11.7674 \\
\hline 3 & -13.4986 & -13.2065 & -6.7376 & -10.3112 & -11.8017 & -11.0831 \\
\hline Delta & 6.0092 & 7.1950 & 8.4651 & 8.0705 & 1.6846 & 1.4451 \\
\hline Rank & 4 & 3 & 1 & 2 & 5 & 6 \\
\hline
\end{tabular}

Table 3. The results of ANOVA for the designed orthogonal array design in the optimization of gIONPs synthesis parameters. 


\begin{tabular}{|c|c|c|c|c|c|}
\hline \multicolumn{6}{|l|}{ Analysis of Variance (ANOVA) } \\
\hline Parameters & DF & Adj SS & Adj MS & F-Value & P-Value \\
\hline Extract Concentration (w/w \%) & 2 & 5.310 & 5.310 & 5.15 & 0.021 \\
\hline Iron Ion (M) & 2 & 28.023 & 28.023 & 27.18 & 0.000 \\
\hline Time (h) & 2 & 37.887 & 37.887 & 36.75 & 0.000 \\
\hline Temp $\left({ }^{\circ} \mathrm{C}\right)$ & 2 & 46.776 & 46.776 & 45.37 & 0.000 \\
\hline RPM & 2 & 1.921 & 1.921 & 1.86 & 0.192 \\
\hline $\mathrm{pH}$ of extract & 2 & 2.410 & 2.410 & 2.34 & 0.133 \\
\hline Error & 14 & 7.216 & 7.216 & & \\
\hline Total & 26 & 129.543 & & & \\
\hline
\end{tabular}

\section{Characterization of gIONPs at optimum synthesis parameters}

A follow-up characterization analysis was carried out considering the optimum values of synthesis parameters for gIONPs. The hydrodynamic size and PDI value of gIONPs at the optimum parameters were measured as $78 \pm 22 \mathrm{~nm}$ and $0.42 \pm 0.06$, respectively (Fig.2(a)). gIONPs sample was measured at an average zeta potential of $+40.75 \pm 1.22 \mathrm{mV}$ (Fig.2(b)). The stability of nanoparticle solutions can be obviously predicted by zeta potential measurements. The particles tend to agglomerate as the electric potential approaches zero. Particles tend to repel other particles at the zeta potential of either more than $+20 \mathrm{mV}$ or less than $-20 \mathrm{mV}$ [25].

The formation of gIONPs in the aqueous colloidal solution was confirmed by the peak at $299 \mathrm{~nm}$ using UV-visible spectral analysis (Fig.3). As per the previously reported literature, this is due to the green biosynthesis of iron oxide nanoparticles [26]. The absorbance peak of iron oxide nanoparticles synthesized using plant extract ranged from 240 to $360 \mathrm{~nm}$ [27] [28]. The X-ray diffraction of glONPs was recorded at $2 \theta$ values ranging from $10^{\circ}-80^{\circ}$ (Fig. 4). XRD spectrum showed distinct peaks at $24.20^{\circ}$, $33.18^{\circ}, 35.68^{\circ}, 40.90^{\circ}, 49.54^{\circ}, 54.17^{\circ}, 62.47^{\circ}$, and $64.12^{\circ}$, which indicates the crystalline nature of the iron oxide nanoparticles and corresponds to the hematite (JCPDS No. 013-0534) (Table S2) [29] [30]. The average crystallite size of the nanoparticles was calculated as $5.09 \mathrm{~nm}$ using Debye-Scherrer's equation.

Fig.5(b) and Fig.5(c) present the images of iron oxide nanoparticles captured by transmission electron microscopy (TEM). The TEM images showed that the nanoparticles are in a spherical shape and some of the particles were agglomerated. In the absence of coating materials, iron oxide nanoparticles that form part of a colloid tend to agglomerate. These agglomerates may be caused by either strong or weak physical interactions [33].

The gIONPs at optimum conditions were also characterized by energy-dispersive X-ray spectroscopy (EDX) to examine their composition. EDX was built in the microscope by which the SEM image of the 
sample was recorded. The EDX spectrum is presented in Fig.6. The atomic percentages are $33.14 \%$ of oxygen and $64.26 \%$ of iron. The EDX confirmed the presence of both iron and oxygen which indicates the reduction of iron ions to iron oxide by carob pod extract. The $\mathrm{Cl}$ signal was detected originating from iron chloride precursor salt used in the synthesis protocol and from the plant biomaterial used for the synthesis of nanoparticles. The signals for $\mathrm{K}$ were observed which may originate from the plant biomaterial [34] .

FTIR spectroscopy for the extract and gIONPs solution was carried out. It was observed that the soluble elements present in plant extract acted as capping agents of gIONPs due to the FTIR analysis. The spectra of the carob pod extract revealed absorption bands at $3493,3120,1708,1377,1040,803$, and $626 \mathrm{~cm}^{-1}$, while the absorption bands of synthesized gIONPs were observed at 3028, 2080, 1680, 1390, 1047, 917, and $470 \mathrm{~cm}^{-1}$ (Fig.7).

The band at $3493 \mathrm{~cm}^{-1}$ is an indicator of stretching in the $\mathrm{OH}$ group within free hydroxyl [35]. The band located at $3120 \mathrm{~cm}^{-1}$ is assigned to stretching of $\mathrm{O}-\mathrm{H}$ group bond in galactose sugar compound in carob pod extract [36]. The band in $1708 \mathrm{~cm}^{-1}$ shows the presence of unsaturated carbonyl groups [37]. The band in $1377 \mathrm{~cm}^{-1}$ is attributed to the symmetrical stretch of the methyl functional group [38]. The band at $1040 \mathrm{~cm}^{-1}$ can be assigned to the stretching vibration of $\mathrm{C}-\mathrm{N}$ function groups in plant polyphenolic species [39]. The band in $626 \mathrm{~cm}^{-1}$ shows the C-S stretching [40]. The band in $3028 \mathrm{~cm}^{-1}$ is attributed to the $\mathrm{C}-\mathrm{H}$ and $\mathrm{C}-\mathrm{O}$ bending and stretching of oleic acids [41]. The band in $2080 \mathrm{~cm}^{-1}$ is also a typical band of stretching bands of unbound CO [42]. The absorption bands at 1047, 1680, and 1390 $\mathrm{cm}^{-1}$ were assigned to the strong $\mathrm{C}=\mathrm{O}$ stretching band related to the carbonyl group and medium $\mathrm{C}-\mathrm{H}$ bending, respectively [43]. The band at the $917 \mathrm{~cm}^{-1}$ is attributed to the $\mathrm{C}-\mathrm{H}$ bending due to the carbohydrate. The formation of gIONPs is characterized by the absorption bands from 428 to $686 \mathrm{~cm}^{-1}$. The band at $470 \mathrm{~cm}^{-1}$ corresponds to the Fe- 0 vibration bonds related to the octahedral units of the magnetite phase [44] [45]. This band was absent in plant extract which indicates the formation of iron oxide nanoparticles. A similar observation has been reported by several studies [46] [47].

\section{Stability analysis of colloidal gIONPs at optimum synthesis parameters}

The $\mathrm{pH}$ and zeta potential of colloidal gIONPs solution was measured as 1.9 and $+42.5 \mathrm{mV}$ after synthesis, respectively. The schematic representation of zeta potential is seen in Fig.8. The pH of the isoelectric point of the gIONPs was determined as 6.8 by the zeta potential measurements (Fig.9(a)). The gIONPs began to agglomerate at pH values greater than 5 and less than 11 (Fig.9(b)). The stability of the colloidal gIONPs solution was evaluated by monitoring the zeta potentials over 3 months (Table 4). The high stability of gIONPs is defined by their high electrostatic potential. A similar study has been performed for the iron oxide nanoparticles synthesized using the aqueous coprecipitation method and it was observed that the zeta potential of nanoparticles was constant at around $-39 \mathrm{mV}$ for long-term storage (over 16 months) [48] . 
Table 4. Zeta potential measurement of gIONPs nanoparticles over 3 months

\begin{tabular}{|c|c|c|}
\hline Time (month) & Zeta Potential $(\mathrm{mV})$ & $\mathrm{pH}$ \\
\hline 0 & +42.5 & 1.92 \\
\hline 1 & +41.0 & 1.91 \\
\hline 2 & +40.4 & 1.95 \\
\hline 3 & +40.8 & 1.90 \\
\hline
\end{tabular}

The UV-vis absorbance spectrum of gIONPs colloidal solution over 3 months was monitored and the maximum absorbance did not change during this period (Fig.10). Metal nanoparticles exhibit surface plasmon resonance (SPR) absorption dependent on the size, shape, and composition [49]. According to this phenomenon, it could be explained that gIONPs were formed with good stability and the composition did not change due to the formation of agglomerates during the 3 months period [50]. Shoaib et al. have carried out similar stability experiments with green silver nanoparticles using UV-vis spectroscopy and they indicated the change of the maximum absorbance due to the presence of agglomerations [51].

\section{Antibacterial activity evaluation of gIONPs}

Agar well diffusion method was employed to evaluate the antibacterial activity of powder form of glONPs against the Gram-negative (Escherichia coli) and Gram-positive (Staphylococcus aureus) bacteria species. gIONPs showed clear zones of inhibition of $24 \mathrm{~mm}$ and $21 \mathrm{~mm}$ in $250 \mathrm{mg} / \mathrm{mL}$ concentration against $S$. aureus and $E$. coli bacteria respectively. The negative control of Ceratonia siliqua L. extract had no effect on microbial growth whereas the standard antibiotics selected as positive control showed inhibition on the selected microorganisms. The inhibition activity of the glONPs were compared with standard antibiotics Cefoxitin, Cefotaxime, Gentamicin, and Tetracycline shown in Table 5. The results were compared with the standard Kirby Bauer interpretation chart (Table S3). The Gram-positive Staphylococcus aureus bacteria was found to be more susceptible to gIONPs than the Gram-positive pathogens Escherichia coli. glONPs showed the highest inhibition zone against $S$. aureus when compared with 4 standard antibiotics. The antibacterial property of gIONPs showed a greater inhibition activity against Gram positive than Gram negative bacteria (Fig.11). This might be because of the differences in cell wall composition of bacteria [52].

Table 5. Zone inhibition of gIONPs, Ceratonia siliqua L. extract and standard antibiotics against selective bacterial strains. 


\section{Zone of Inhibition (Diameter in $\mathrm{mm}$ )}

\begin{tabular}{l|c|c|} 
& \multicolumn{1}{c}{ S. aureus } & E. coli \\
\hline Ceratonia siliqua L. Extract & - & - \\
\cline { 2 - 3 } Cefoxitin (FOX) $(30 \mu \mathrm{g} /$ disc $)$ & $11.87 \pm 0.14$ & $28.46 \pm 0.11$ \\
\cline { 2 - 3 } Cefotaxime (CTX) $(30 \mu \mathrm{g} /$ disc $)$ & - & $14.27 \pm 0.09$ \\
\cline { 2 - 3 } Gentamicin (CN) $(10 \mu \mathrm{g} /$ disc) & $23.62 \pm 0.16$ & $22.83 \pm 0.08$ \\
\cline { 2 - 3 } Tetracycline $(\mathrm{TE})(30 \mu \mathrm{g} /$ disc $)$ & $10.5 \pm 0.15$ & $23.92 \pm 0.14$ \\
\cline { 2 - 3 } gIONPs $(250 \mathrm{mg} / \mathrm{mL})$ & $24.27 \pm 0.12$ & $20.83 \pm 0.11$ \\
\hline
\end{tabular}

The inhibitory action of gIONPs may be attributed to the oxidative stress by reactive oxygen species generation and the Fenton reaction [53]. When iron nanoparticles penetrate cells through disrupted membranes, it may cause further damage. Li et al. found that the iron oxide nanoparticles not only inhibited $E$. coli cell growth, but also caused bacterial cell death due to the production of significantly elevated reactive oxygen species (ROS) such as hydroxyl radicals, superoxide radicals, singlet oxygen, and hydrogen peroxide levels [54]. Das et al. performed the ROS measurement studies of $S$. aureus in presence of iron oxide nanoparticles. They found that iron oxide nanoparticles enhance the fluorescence intensity significantly which is directly correlated with the quantity of ROS developed at $S$. aureus bacterial cells. [55]. Similar results of the antibacterial effect of iron nanoparticles on S. aureus and E. coli have been reported in recent studies. Kanagasubbulakshmi and Kadirvelu evaluated the antibacterial property of iron oxide nanoparticles against Gram negative - E. coli and Gram positive- S. aureus. They found the zone of inhibition of $10 \mathrm{~mm}$ and $8 \mathrm{~mm}$ for Escherichia coli and Staphylococcus aureus, respectively [56]. Suganya et al. reported considerable antibacterial activity of iron oxide nanoparticles from leaf extract of Passiflora foetida towards Gram negative and positive bacteria. They found the zone of inhibition for Staphylococcus aureus and Escherichia coli as $11 \mathrm{~mm}$ and $18 \mathrm{~mm}$, respectively [57]. Amutha and Sridhar used the Glycosmis mauritiana leaf extract for the formation of iron oxide nanoparticles and evaluated its application on antibacterial activity against the tested pathogens of $E$. coli and S. aureus. They found the minimum zone of inhibition as $12 \mathrm{~mm}$ and $8 \mathrm{~mm}$ for the $10 \mu \mathrm{g} / \mathrm{disc}$ of green synthesized iron oxide nanoparticles [58] .

\section{Conclusion}

The potential of Ceratonia siliqua L. aqueous extract for the simple and one-pot green synthesis of iron oxide nanoparticles was investigated. This study focused on the optimization of the green synthesis parameters for the stable colloidal form of gIONPs and evaluation of the antibacterial effect of the gIONPs powder against Gram-negative (Escherichia coli) and Gram-positive (Staphylococcus aureus) bacteria. Optimum synthesis parameters were found to be efficient in terms of synthesis of narrow-sized as well as stable nanoparticles. Reaction time and temperature were the most effective parameters in the iron oxide nanoparticle synthesis reaction. The $\mathrm{pH}$ of extract and stirring rate showed no significant effects. The biomaterials from the Ceratonia siliqua L. extract successfully achieved the monodispersed 
and stable gIONPs for 3 months period. The particles were effectively surrounded by biomaterials without any external addition of surfactant and polymers. Powder form of gIONPs also showed antibacterial activity against both Gram-negative (Escherichia coli) and Gram-positive (Staphylococcus aureus). The gIONPs inhibited the growth of Staphylococcus aureus with high susceptibility when compared with the standard antibiotics of Cefotaxime, Tetracycline, Gentamicin, and Cefoxitin and also the growth of Escherichia coli when compared with the standard antibiotics of Tetracycline and Gentamicin. gIONPs could serve as a potential antibacterial agent.

\section{Declarations}

\section{Author Contributions}

Derya Aksu Demirezen: Methodology, Data curation, Investigation, Writing - original draft. Şeyda Yılmaz: Methodology, Data curation. Dilek Demirezen Yılmaz: Methodology, Resources. Yalçın Şevki Yıldız: Resources, Funding.

\section{Conflict of Interest}

The authors declare that they have no known competing financial interests or personal relationships that could have appeared to influence the work.

\section{Acknowledgment}

This study was financially supported by Erciyes University Scientific Research Projects Coordination department with a project number of FDK-2021-10896.

\section{References}


[1] T. R. Ray, B. Lettiere, J. d. Rutte and S. Pennathur, "Quantitative Characterization of the Colloidal Stability of Metallic Nanoparticles Using UV-vis Absorbance Spectroscopy," Langmuir, vol. 31, pp. 3577-3586, 2015.

[2] J. Singh, T. Dutta, K. Kim, M. Rawat, P. Samddar and P. Kumar, "'Green' synthesis of metals and their oxide nanoparticles: applications for environmental remediation," Journal of Nanobiotechnology, vol. 16, p. 84, 2018.

[3] M. Herlekar, S. Barve and R. Kumar, "Plant-Mediated Green Synthesis of Iron Nanoparticles," Journal of Nanoparticles, vol. 2014, p. 140614, 2014.

[4] J. K. Patra and K. Baek, "Green Nanobiotechnology: Factors Affecting Synthesis and Characterization Techniques," Journal of Nanomaterials, vol. 2014, no. 417305, 2014.

[5] R. Krishnamoorthi, S. Bharathakumar, B. Malaikozhundan and P. U. Mahalingam, "Mycofabrication of gold nanoparticles: Optimization, characterization, stabilization and evaluation of its antimicrobial potential on selected human pathogens," Biocatalysis and Agricultural Biotechnology, vol. 35, no. 102107, 2021.

[6] A. Nene, K. W. M. Takahashi and M. Umeno, "Size controlled synthesis of Fe3O4 nanoparticles by ascorbic acid mediated reduction of Fe(acac) 3 without using capping agent," Journal of Nano Research 2016, pp. 8-19, 2016.

[7] N. Ajinkya, X. Yu, P. Kaithal, H.Luo, P. Somani and S. Ramakrishna, "Magnetic Iron Oxide Nanoparticle (IONP) Synthesis to Applications: Present and Future," Materials, vol. 13, 2020.

[8] J. Kudr, Y. Haddad, L. Richtera, Z. Heger, M. Cernak, V. Adam and O. Zitka, "Magnetic nanoparticles: from design and synthesis to real world applications," Nanomaterials (Basel), vol. 7, 2017.

[9] Q. Feng, Y. Liu, J. Huang, K. Chen, J. Huang and K. Xiao, "Uptake, distribution, clearance, and toxicity of iron oxide nanoparticles with different sizes and coatings," Scientific Reports, vol. 2018, p. 2082, 2018.

[10] W. Li, D. Liu, J. Wu, C. Kim and J. D. Fortner, "Aqueous Aggregation and Surface Deposition Processes of Engineered Superparamagnetic Iron Oxide Nanoparticles for Environmental Applications," Environmental Science \& Technology, vol. 48, p. 11892-11900, 2014.

[11] V. Velmurugan, G. Arunachalam and V. Ravichandran, "Antibacterial activity of stem bark of Prosopis cineraria (Linn.) druce," Archives of Applied Science Research, vol. 2, pp. 147-150, 2010.

[12] F. A. Ayaz, H. Torun, S. Ayaz, P. J. Correira, M. Alaiz, C. Sanz, J. Grux and M. Strnad, "Determination of chemical composition of Anatolian carob pod (Ceratonia Siliqua L.): Sugars, amino and organic acids, minerals and phenolic compounds," Journal of Food Quality, vol. 30, pp. 1040-1055, 2007.

[13] S. K. Karna, R. V.Singh and R. S. , "Application of Taguchi method in process optimization," in Proceedings of the National Conference on Trends and Advances in Mechanical Engineering, Faridabad, 2012.

[14] D. A. Demirezen, Y. Ş. Yıldız, Ş. Yılmaz and D. Demirezen Yılmaz, "Green synthesis and characterization of iron oxide nanoparticles using Ficus carica (common fig) dried fruit extract," Journal of Bioscience and Bioengineering, vol. 127, pp. 241-245, 2019.

[15] M. Danaei, M. Dehghankhold, S. Ataei, F. H. Davarani, R. Javanmard, A. Dokhani, S. Khorasani and M. R. Mozafari, "Impact of Particle Size and Polydispersity Index on the Clinical Applications of Lipidic Nanocarrier Systems," Pharmaceutics, vol. 10, p. 57, 2018, 10, 57. 
[16] K. Tahir, S. Nazir, B. Li, A. U. Khan, Z. U. H. Khan, A. Ahmad and F. U. Khan, "An efficient photo catalytic activity of green synthesized silver nanoparticles using Salvadora persica stem extract," Separation and Purification Technology, vol. 150, pp. 316-324, 2015.

[17] R. A. Hamouda, M. H. Hussein, R. A. Abo-elmagd and S. Bawazir, "Synthesis and biological characterization of silver nanoparticles derived from the cyanobacterium Oscillatoria limnetica," Scientific Reports, vol. 9, no. 13071, 2019.

[18] M. Y. Junaidi, E. S. Harsojo and T. Kuwat, "Effect of Stirring Rate on The Synthesis Silver Nanowires using Polyvinyl Alcohol as A Capping Agent by Polyol Process," International Journal on Advanced Science, Engineering and Information Technology, vol. 6, pp. 365-369, 2016.

[19] K. Kartini, A. Alviani, D. Anjarwati, A. F. Fanany, J. Sukweenadhi and C. Avanti, "Process Optimization for Green Synthesis of Silver Nanoparticles Using Indonesian Medicinal," Processes, vol. 8, p. 998, 2020.

[20] J. Saxena, P. K. Sharma, M. M. Sharma and A. Singh, "Process optimization for green synthesis of silver nanoparticles by Sclerotinia sclerotiorum MTCC 8785 and evaluation of its antibacterial properties," Springer Plus, vol. 5, p. 861, 5, 861 (2016).

[21] S. Satpathy, A. Patra, B. Ahirwar and M. D. Hussain, "Process optimization for green synthesis of gold nanoparticles mediated by extract of Hygrophila spinosa T. Anders and their biological applications," Physica E: Low-dimensional Systems and Nanostructures, vol. 121, p. 113830, 2020 .

[22] S. Ahmed, Saifullah, M. Ahmad, B. L. Swami and S. Ikram, "Green synthesis of silver nanoparticles using Azadirachta indica aqueous leaf extract," Journal of Radiation Research and Applied Sciences, vol. 9, pp. 1-7, 2016.

[23] R. Kheshtzar, A. Berenjian, S. M. Taghizadeh and Y. Ghasemi, "Optimization of reaction parameters for the green synthesis of zero valent iron nanoparticles using pine tree needles," Green Processing and Synthesis, vol. 8, pp. 846-855, 2019.

[24] A. Gholami, R. Khosravi, A. Khosravi and Z. Samadi, "Data on the optimization of the synthesis ofgreen iron nanoparticles using plants indigenousto South Khorasan," Data in Brief, vol. 21, pp. 1779-1783, 2018.

[25] F. H. Bijarbooneh, Y. Zhao, J. H. Kim, Z. Sun, V. Malgras, S. H. Aboutalebi, Y.-U. Heo, M. Ikegami and S. X. Dou, "Aqueous Colloidal Stability Evaluated by Zeta Potential Measurement and Resultant TiO2 for Superior Photovoltaic Performance," Journal of the American Ceramic Society, vol. 96, pp. 2636-2643, 2013.

[26] J. K. Patra and K. Baek, "Green biosynthesis of magnetic iron oxide (Fe304) nanoparticles using the aqueous extracts of food processing wastes under photo-catalyzed condition and investigation of their antimicrobial and antioxidant activity," Journal of Photochemistry and Photobiology B: Biology, vol. 173, pp. 291-300, 2017.

[27] E. C. Njagi, H. Huang, L. Stafford, H. Genuino, H. M. Galindo, J. B. Collins, G. E. Hoag and S. L. Suib, "Biosynthesis of Iron and Silver Nanoparticles at Room Temperature Using Aqueous Sorghum Bran Extracts," Langmuir, vol. 27, pp. 264-271, 2011.

[28] B. Kumar, K. Smita, L. Cumbal, A. Debut, S. Galeas and V. H. Guerrero, "Phytosynthesis and photocatalytic activity of magnetite (Fe3O4) nanoparticles using the Andean blackberry leaf," Materials Chemistry and Physics, vol. 179, pp. 310-315, 2016.

[29] M. Takeda, T. Onishi, S. Nakakubo and S. Fujimoto, "Physical Properties of Iron-Oxide Scales on Si-Containing Steels at High Temperature," Materials Transactions, vol. 50, pp. 2242-2246, 2009. 
[30] D. Maity and D. Agrawal, "Synthesis of iron oxide nanoparticles under oxidizing environment and their stabilization in aqueous and non-aqueous media," Journal of Magnetism and Magnetic Materials, vol. 308, pp. 46-55, 2007.

[31] D. Rosicka and J. Sembera, "Changes in the nanoparticle aggregation rate due to the additional effect of electrostatic and magnetic forces on mass transport coefficients," Nanoscale Research Letters, vol. 8, pp. 1-9, 2013.

[32] S. S. U. Rahman, M. T. Qureshi, K. Sultana, W. Rehman, M. Y. Khan, M. H. Asif, M. Farooq and N. Sultana, "Single step growth of iron oxide nanoparticles and their use as glucose biosensor," Results in Physics, vol. 7, pp. 4451-4456, 2017.

[33] L. Gutiérrez, L. d. I. Cueva, M. Moros, E. Mazarío, S. d. Bernardo, J. M. d. I. Fuente, M. P. Morales and G. Salas, "Aggregation effects on the magnetic properties of iron oxide colloids," Nanotechnology, vol. 30, p. 112001, 2019.

[34] J. Jeyasundari, P. S. Praba, Y. B. A. Jacob, V. S. Vasantha and V. Shanmugaiah, "Green Synthesis and Characterization of Zero Valent Iron Nanoparticles from the Leaf Extract of Psidium Guajava Plant and Their Antibacterial Activity," Chemical Science Review and Letters, vol. 6, pp. 1244-1252, 2017.

[35] G. Nikaeen, S. Yousefinejad, S. Rahmdel, F. Samari and S. Mahdavinia, "Central Composite Design for Optimizing the Biosynthesis of Silver Nanoparticles using Plantago major Extract and Investigating Antibacterial, Antifungal and Antioxidant Activity," Scientific Reports, vol. 10, no. 9642,2020 .

[36] B. Guven, S. Durakli-Velioglu and I. H. B. S., "Rapididentification of some sweeteners and sugars by attenuated total reflectance-fourier transform infrared (atr-ftır), near-Infrared (nır) and raman spectroscopy.," Gıda, vol. 44, pp. 274-290, 2019.

[37] P. Rajiv, A. Deepa, P. Vanathi and D. Vidhya, "Screenıng For Phytochemıcals And Ftır Analysıs Of Myristica Dactyloıds Fruit Extracts," International Journal of Pharmacy and Pharmaceutical Sciences, vol. 9, pp. 315-318, 2017.

[38] J. Coates, "Interpretation of Infrared Spectra, A Practical Approach," Infrared Spectroscopy, 2006.

[39] F. U. Khan, Y. Chen, N. U. Khan, A. Ahmad, K. Tahir, Z. U. Khan, A. U. Khan, S. U. Khan, M. Raza and P. Wan, "Visible light inactivation of E. coli, Cytotoxicity and ROS determination of biochemically capped gold nanoparticles," Microbial Pathogenesis, vol. 107, pp. 419-424, 2017.

[40] M. K. Trivedi, S. Patil, H. Shettigar, K. Bairwa and S. Jana, "Effect of Biofield Treatment on Spectral Properties of Paracetamol and Piroxicam," Chemical Sciences Journal, vol. 6, p. $100098,2015$.

[41] Y. Hou, C.Hou, Y. Fan, F. Dang and B. W. Li, "Biphasic liquid interface derived magnetite nanocrystals: synthesis, properties and growth mechanism," Materials Research Express, vol. 4, 2017.

[42] M. Horn, K. Nienhaus and G. U. Nienhaus, "Fourier transform infrared spectroscopy study of ligand photodissociation and migration in inducible nitric oxide synthase," F1000 Research, vol. 3, 2014.

[43] F. B. G. Camara, L. A. Costa, G. P. Fidelis, L. T. D. B. Nobre, N. Dantas-Santos, S. L. Cordeiro, L. G. A. M. S. S. P. Costa and H. A. O. Rocha, "Heterofucans from the Brown Seaweed Canistrocarpus cervicornis with Anticoagulant and Antioxidant Activities," Marine Drugs, vol. 9, pp. 124-138, 2011. 
[44] S. M. El-Sigeny and M. F. A.Taleb, "Synthesis, Characterization, and Application of Dendrimer Modified Magnetite Nanoparticles as Antimicrobial Agent," Life Science Journal , vol. 12, 2015.

[45] S. Rada, A. Dehelean and E. Culea, "FTIR, Raman, and UV-Vis spectroscopic and DFT investigations of the structure of iron-lead-tellurate glasses," Journal of Molecular Modeling, vol. 17, pp. 2103-2111, 2011.

[46] A. K. Das and R. V. A. Marwal, " Bio-reductive synthesis and characterization of plant protein coated magnetite nanoparticles," In Nano Hybrids, vol. 7, pp. 69-86, 2014.

[47] W. Lu, Y. Shen, A. Xie and W. Zhang, "Green synthesis and characterization of superparamagnetic Fe304 nanoparticles," Journal of Magnetism and Magnetic Materials, vol. 322, pp. 1828-1833, 2010.

[48] D. Kovář, A. Malá, J. Mlčochová, M. Kalina, Z. F. Hlaváček, Antonín, Z. Farka, P. Skládal, Z. Starčuk, R. Jiř́k, O. Slabý and J. Hubálek, "Preparation and Characterisation of Highly Stable Iron Oxide Nanoparticles for Magnetic Resonance Imaging," Journal of Nanomaterials, vol. 2017, p. 7859289, 2017.

[49] C. F. Bohren and D. R. Huffman, in Absorption and Scattering of Light by Small Particles, New York, WILEY-VCH Verlag GmbH \& Co. KGaA, 2007, pp. 1-11.

[50] V. T. L. Huong and N. N. Thang, "Green synthesis, characterization and antibacterial activity of silver nanoparticles using Sapindus mukorossi fruit pericarp extract," Materials Today: Proceedings, vol. 42, pp. 88-93, 2021.

[51] M. Shoaib, A. Naz, F. A. Osra, S. H. Abro, S. U. Qazi, F. A. Siddiqui, M. R. Shah and A. Z. Mirza, "Green synthesis and characterization of silver-entecavir nanoparticles with stability determination," Arabian Journal of Chemistry, vol. 14, p. 102974, 2021.

[52] M. G. Guzman, J. Dille and S. Godet, "Synthesis and antibacterial activity of silver nanoparticles against Gram-positive and Gram negative bacteria," Nanomedicine: Nanotechnology, Biology and Medicine, vol. 8, no. 1, pp. 37 - 45, 2012.

[53] Y. M. Mohamed, A. M. Azzam, B. H. Amin and N. A. Safwat, "Mycosynthesis of iron nanoparticles by Alternaria alternata and its antibacterial activity," African Journal of Biotechnology, vol. 14, no. 14, pp. 1234-1241, 2015.

[54] Y. Li, D. Yang, S. Wang, C. Li, B. Xue, L. Yang, Z. Shen, M. Jin, J. Wang and Z. Qiu, "The Detailed Bactericidal Process of Ferric Oxide Nanoparticles on E. coli," Molecules, vol. 23, no. 3, p. 606, 2018.

[55] S. Das, S. Diyali, G. Vinothini, B. Perumalsamy, G. Balakrishnan, T. Ramasamy, D. Dharumadurai and B. Biswas, "Synthesis, morphological analysis, antibacterial activity of iron oxide nanoparticles and the cytotoxic effect on lung cancer cell line," Heliyon, vol. 6, no. 9, p. e04953, 2020.

[56] S. Kanagasubbulakshmi and K. Kadirvelu, "Green Synthesis of Iron Oxide Nanoparticles using Lagenaria Siceraria and Evaluation of its Antimicrobial Activity," Defence Life Science Journal, vol. 2, no. 4, pp. 422-427, 2017.

[57] D. Suganya, M. R. Rajan and R. Ramesh, "Green synthesis of iron oxide nanoparticles from Leaf extract of Passiflora Foetida and its antibacterial activity," International Journal of Current Research, vol. 8, no. 11, pp. 42081-42085, 2016.

[58] S. Amutha and S. Sridhar, "Green synthesis of magnetic iron oxide nanoparticle using leaves of Glycosmis mauritiana and their antibacterial activity against human pathogens," Journal of Innovations in Pharmaceutical and Biological Sciences (JIPBS), vol. 5, no. 2, pp. 22-26, 2018. 
Figures

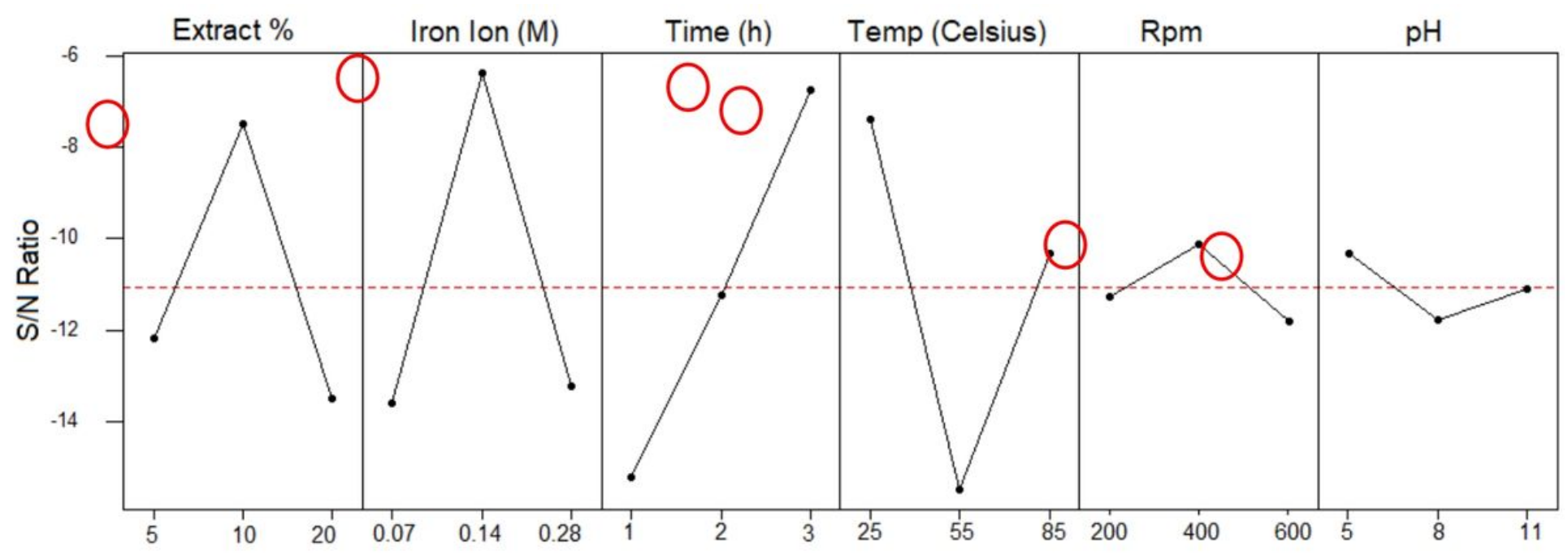

Figure 1

Main effects plot of $\mathrm{S} / \mathrm{N}$ ratio for smallest $\mathrm{PDI}$ value.

Figure 2

(a) The particle size distribution and (b) zeta potential of colloidal gIONPs.

Figure 3

UV/Vis absorption spectrum of colloidal gIONPs. 


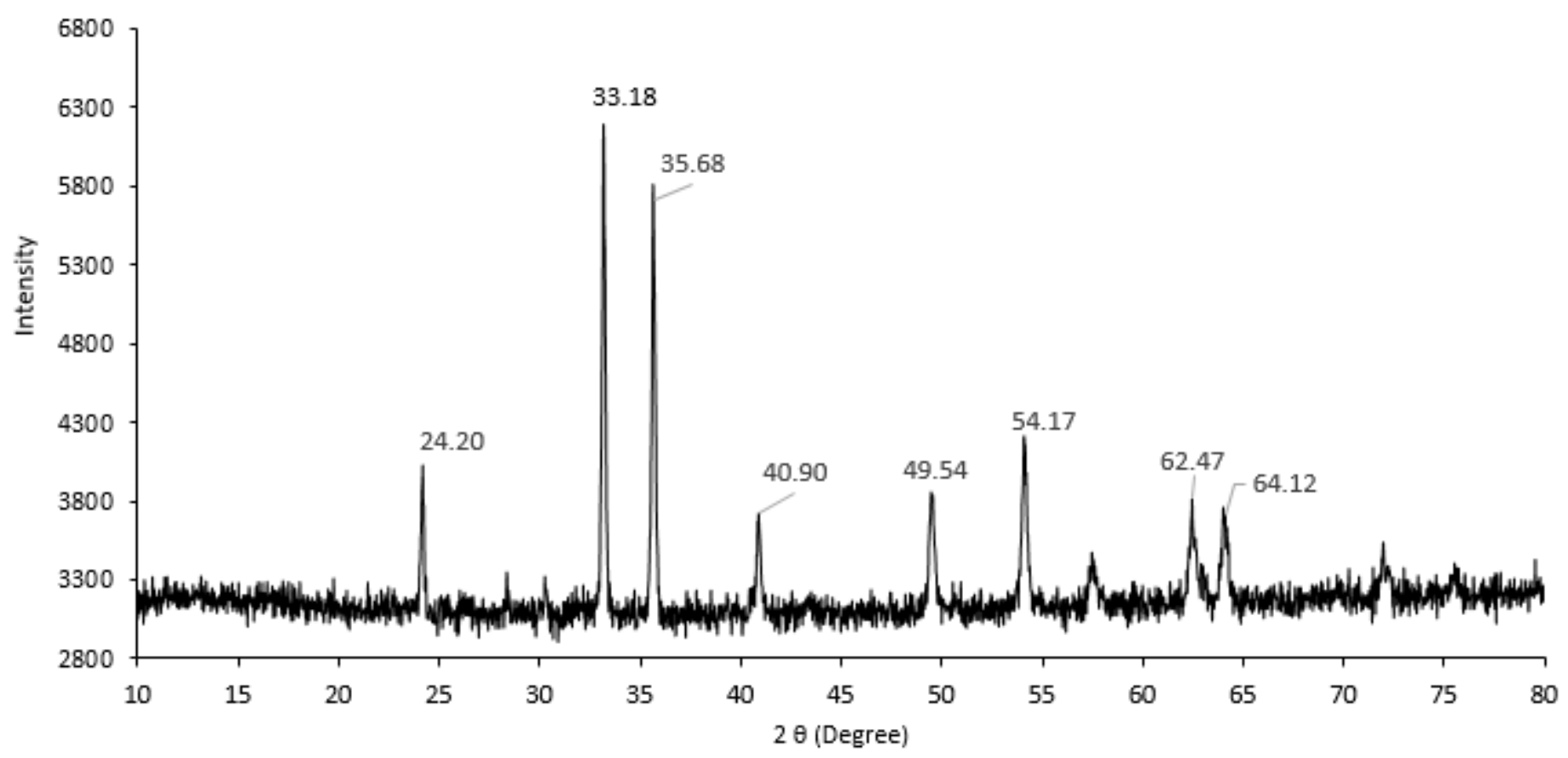

Figure 4

XRD pattern of gIONPs.

Figure 5

(a) SEM image and TEM images of (b) distribution and (c) size and shape of gIONPs.

Figure 6

EDX analysis of gIONPs.

Figure 7

FTIR spectra of colloidal gIONPs and carob pod extract.

Figure 8 
Schematic representation of zeta potential of colloidal gIONPs.

\section{Figure 9}

(a) Zeta potential versus $\mathrm{pH}$ plot for colloidal gIONPs and (b) images of glONPs colloidal solution at different $\mathrm{pH}$ values.

\section{Figure 10}

UV-Vis absorption spectra of colloidal gIONPs over 3 months.

\section{Figure 11}

(a) Antibacterial activity of gIONPs, Ceratonia siliqua L. Extract, and standard broad-spectrum antibiotics (Cefoxitin (FOX), Cefotaxime (CTX), Gentamicin (CN), and Tetracycline (TE)) against S. aureus and E. coli bacteria (b)-(c) The plates showing the inhibition zones of gIONPs and Ceratonia siliqua L. Extract, and standard broad-spectrum antibiotics (Cefoxitin (FOX), Cefotaxime (CTX), Gentamicin (CN), and Tetracycline (TE)) against $S$. aureus and E. coli bacteria.

\section{Supplementary Files}

This is a list of supplementary files associated with this preprint. Click to download.

- Appendix.docx 